\title{
Impaired response to $\mathrm{B}$ adrenergic stimulation of L-type $\mathrm{Ca}$ current in ventricular cells from the SHR heart
}

Yoshizumi Habuchi, Ling-Ling Lu, Iaku Yamamoto, Manabu Nishio,

Junichiro Morikawa, Toshiaki Komori, Shigetaka Okamoto, and Manabu Yoshimura

Department of Clinical Laboratory and Medicine, and Third Department of Internal

Medicine

Kyoto Prefectural University of Medicine, Kawaramachi, Kamigyo-ku, Kyoto 602

Japan

The hypertrophic heart muscle has been known to show a larger developed tension and a longer action potential duration as compared with the normal heart (Hart, Cardiovasc Res 28: 933, 1994). Although L-type Ca2+ current $\left(\mathrm{I}_{\mathrm{Ca}}\right)$ is a major determinant of the action potential duration and $\mathrm{Ca}^{2}+$ release from the sarcoplasmic reticulum, several previous studies have demonstrated that its current density is not substantially different between the hypertrophic myocytes and the control myocytes. We compared the stimulatory effects of isoproterenol on $\mathrm{I}_{\mathrm{Ca}}$ between the geneticallyinduced hypertensive rat (SHR) and control rat (WKY).

The whole-cell voltage-clamp method was employed to measure $\mathrm{I}_{\mathrm{Ca}}$ on the enzymatically isolated single left ventricular cells. WKY and SHR were at 8 weeks of the age. The solutions were $\mathrm{K}+$-free. Test pulses were applied from a holding potential of $-40 \mathrm{mV}$. In the experiments where isoproterenol was used to stimulate the $\mathrm{I}_{\mathrm{Ca}}$, the extracellular $\mathrm{CaCl}_{2}$ concentration was reduced to $0.5 \mathrm{mM}$ with $\mathrm{MgCl}_{2}$ substituted to obtain a better voltage control. The temperature was $37^{\circ} \mathrm{C}$.

Neither the current density nor the shape of the current-voltage relationship for $I_{C a}$ in the SHR heart cells was different from those in the WKY cells. However, the stimulatory response to isoproterenol (ISO) was diminished in the SHR cells. The maximal response $\left(E_{\max }\right)$ in response to 1 or $10 \mu \mathrm{M}$ isoproterenol was smaller only by $15 \%$. Whereas, the ED 50 was apparently higher in SHR than in WKY (70 nM for SHR vs. $20 \mathrm{nM}$ for WKY). This reduced $\mathrm{I}_{\mathrm{Ca}}$ sensitivity to isoproterenol in SHR heart can be ascribed to either impaired CAMP production or reduced sensitivity of $\mathrm{Ca}^{2}+$ channels to cAMP. Isobutyl methylxanthine (IBMX), a potent phosphodiesterase inhibitor, caused only a small accentuation of $0.1 \mu \mathrm{M}$ isoproterenol-stimulated $\mathrm{I}_{\mathrm{Ca}}$ in WKY cells.

Whereas, it significantly increased the stimulated $\mathrm{l}_{\mathrm{ca}}$ by $31 \pm 20 \%$ in SHR cells $(n=5)$. The \% increase over the control in response to isoproterenol plus IBMX in these SHR cells was $115 \pm 30 \%$, which was not statistically different from the $E_{\max }$ for the isoproterenol stimulation of $I_{C a}$ in WKY. The $I_{C a}$ in WKY and SHR showed comparable responses to $3 \mu \mathrm{M}$ forskolin. These findings suggest that the CAMP producing systems including the $B$ receptor-adenylate cyclase coupling with $G$ protein are impaired in the SHR cells. Another possibility is that the cAMP degradation by phosphodiesterase is enhanced in the SHR heart. 